\title{
Estrutura e dinâmica de comunidades bentônicas dominadas por macrófitas na zona intramareal da Praia de Jacaraípe, Espírito Santo, Brasil
}

\author{
Sulamita Oliveira Barbosa ${ }^{1,4}$, Marcia A. de O. Figueiredo ${ }^{2}$ e Viviane Testa ${ }^{3}$
}

Recebido: 28.06.2006; aceito: 30.10.2008

ABSTRACT - (Structure and dynamic of benthic communities dominated by macrophytes in Praia de Jacaraípe, Espírito Santo, Brazil). The partially exposed reef bank of Praia de Jacaraípe is built by up to $40 \mathrm{~cm}$ thickness of crustose coralline red algae upon a Holocene reef community. This work aims to describe the flora composition and phytobenthic structure of this community that has not been studied yet. The survey was carried out during winter and summer. On the reef flat and reef border ten randon quadrats were sampled along $20 \mathrm{~m}$ transect in each habitat. There were twelve chlorophytes, four phaeophytes, 34 rhodophytes and one seagrass, totalizing 35 genera and 51 taxa. There was a seasonal variation of species richness only on the reef flat, less rich in winter. The articulate calcareous red algae had greater biomass and surface cover in both seasons. The space and temporal distribution of the flora is in agreement with the substrate type, hydrodynamic and seawater turbidity patterns found elsewhere in Brazil.

Key words: community structure, intertidal zone, macroalgae, seagrass

RESUMO - (Estrutura e dinâmica de comunidades bentônicas dominadas por macrófitas na zona intramareal na Praia de Jacaraípe, Espírito Santo, Brasil). O recife parcialmente exposto da Praia de Jacaraípe é formado por algas calcárias vermelhas incrustantes com até $40 \mathrm{~cm}$ em espessura sobre uma comunidade recifal holocênica. Este trabalho visa descrever a composição da flora atual e estrutura do fitobentos desta comunidade, todavia não estudada. O levantamento ocorreu no verão e inverno, no platô e borda recifal. Foram amostrados 10 quadrados aleatórios ao longo de transectos de $20 \mathrm{~m}$ em cada habitat. Os resultados apontam para a presença de doze clorofíceas, quatro feofíceas, 34 rodofíceas e uma fanerógama marinha, totalizando 35 gêneros e 51 táxons. Foi identificada uma variação sazonal na riqueza específica somente na borda recifal, a qual apresentou uma flora menos rica no inverno. As algas calcárias articuladas tiveram maior biomassa e cobertura nas duas épocas estudadas. A distribuição espacial e temporal da flora está em acordo com padrões de tipo de substrato, hidrodinâmica e turbidez da água do mar encontrados em áreas recifais de todo o Brasil.

Palavras-chave: estrutura de comunidades, fanerógamas marinhas, macroalgas, região intertidal

\section{Introdução}

Os costões rochosos e as formações recifais são os habitats costeiros bentônicos que apresentam alta diversidade (Villaça 2002). Os ecossistemas costeiros do Estado do Espírito Santo/ES apresentam afloramentos que geralmente consistem de rochas do embasamento cristalino, arenitos ferruginosos e rochas de praia e recifes holocênicos (Martin et al. 1996, Kikuchi \& Leão 1998). Os afloramentos de relevo baixo encontrados ao nível do mar, atuam como substrato a ser colonizado por uma biota bentônica rica em macroalgas (Oliveira Filho 1977).

Horta (2001) investigando a distribuição das macroalgas ao longo da costa brasileira, sugere que os grupamentos de macroalgas encontram-se divididos em duas regiões principais: a tropical e a temperada quente, respectivamente no norte/nordeste e sul/sudeste. A transição entre essas duas regiões, representada pelo Estado do Espírito Santo, apresenta características peculiares e alta diversidade específica, estando esta ligada à heterogeneidade de ambientes e às condições de temperatura (Horta 2001, Guimarães 2003).

Os trabalhos taxonômicos mais abrangentes abordando macroalgas do litoral do Espírito Santo iniciaram-se com o levantamento das Ceramiales do sul do estado por Oliveira Filho (1969), seguidos de vários outros trabalhos sobre a sua flora marinha como os de Behar (1972), Guimarães (1990), Guimarães \&

1. Faculdade de Saúde e Meio Ambiente de Vitória, Rodovia Serafim Derenzi 3105, 29048-450 Vitória, ES, Brasil

2. Instituto de Pesquisas Jardim Botânico do Rio de Janeiro, Rua Pacheco Leão 915, 22460-030 Rio de Janeiro, RJ, Brasil

3. Universidade Federal do Espírito Santo. Av. Fernando Ferrari 514, 29075-900 Vitória, ES, Brasil

4. Autor para correspondência: sulamittta@yahoo.com.br 
Pereira (1993), Crispino (2000), Nassar et al. (2001) e Barata (2004). Em contraste, os trabalhos de cunho ecológico são escassos podendo-se citar os trabalhos sobre a estrutura de comunidades fitobentônicas realizados por Gomes et al. (1989), Mitchel et al. (1990), Arantes et al. (1995) e Pereira (1999).

Sendo o litoral do Espírito Santo uma região de transição, faz-se importante a compreensão da abundância dos grupos de algas bentônicas regional, em função dos potenciais distúrbios a que são submetidas. Em estudos que descrevem a estrutura das comunidades bentônicas, Steneck \& Dethier (1994), sugerem o uso de grupos morfo-funcionais de algas marinhas, caracterizados pela semelhança entre espécies que tem as mesmas características morfológicas e anatômicas críticas.

Desse modo, os grupamentos de macroalgas podem ser divididos em sete categorias: microalgas, algas filamentosas, algas foliáceas, algas cilíndricocorticadas, algas coriáceas, algas calcárias articuladas e algas incrustantes. Como estes padrões morfológicos muitas vezes correspondem às características ecológicas é possível predizer a composição da comunidade e os prováveis níveis de distúrbio no meio ambiente ou o reverso. A dominância e a diversidade dos grupos funcionais, por sua vez, também podem estar relacionadas à produtividade e aos distúrbios potenciais do meio ambiente.

Assim sendo, este trabalho teve o objetivo de identificar as espécies mais freqüentes em relação a possíveis distúrbios ambientais naturais em uma região ainda pouco estudada e descrever a estrutura e dinâmica desta comunidade costeira do Estado do Espírito Santo.

\section{Material e métodos}

Descrição da área de estudo - A Praia de Jacaraípe localiza-se no balneário de Jacaraípe, Município da Serra $\left(20^{\circ} 08^{\prime} 05^{\prime}\right.$ 'S e $\left.40^{\circ} 11^{\prime} 2^{\prime \prime} \mathrm{W}\right)$, correspondendo ao litoral centro-norte do Estado do Espírito Santo (figura 1). O local de estudo nesta praia caracteriza-se por uma estreita faixa arenosa durante os períodos de maré alta, ampliando onde afloram os recifes. A praia apresenta estado intermediário com arrebentação tipo mergulhante/deslizante, com altura igual ou superior a $1 \mathrm{~m}$ (Albino 1999) e a amplitude da maré varia de $-0,2$ a 1,8 m (DHN 2004).

Durante as marés baixas de sizígia, fica exposto um substrato irregular, de até $200 \mathrm{~m}$ de largura ao longo de $300 \mathrm{~m}$ da linha de orla e $200 \mathrm{~m}$ de comprimento, caracterizado por uma comunidade recifal holocênica (morta) que colonizou as crostas lateríticas. As algas calcárias vermelhas incrustantes de crescimento laminar, que variam de 6 a $40 \mathrm{~cm}$ em espessura, formam pontes e cavidades que proporcionam a formação de micro-ambientes (figura 2). Esta comunidade sofre um forte impacto antrópico causado pelo turismo local.

A praia estudada apresenta águas turvas entre os meses de fevereiro e novembro, devido a grande quantidade de sedimentos em suspensão retrabalhados pela energia hidrodinâmica moderada à intensa das ondas e marés. A temperatura do ar, na porção central do Espírito Santo, varia de 17,5 a $32,5^{\circ} \mathrm{C}$ (INMET 2005), com média anual de $22^{\circ} \mathrm{C}$ (Martin et al. 1993), sendo as maiores temperaturas registradas para o mês de fevereiro. A média de precipitação varia entre 1.300 e $1.400 \mathrm{~mm}$, com $80 \%$ de umidade média relativa, sendo a maior pluviosidade encontrada no verão (Albino et al. 2005).

A temperatura da superfície da água do mar é um dos parâmetros mais conservativos ao longo da costa tropical do Brasil; na costa leste ela varia de 30 ${ }^{\circ} \mathrm{C}$ no verão a $27^{\circ} \mathrm{C}$ no inverno (Leão \& Dominguez 2000). A corrente do Brasil (CB), que atinge o litoral do ES, é quente e salina com baixos níveis de produtividade (Oliveira Filho 1977). Sob a CB encontra-se a massa de Água Central do Atlântico Sul (ACAS), caracterizada pela água fria e rica em nutrientes, que penetra na região costeira do Estado durante o verão (Valentin \& Moreira 1978). Os ventos de maior freqüência e intensidade são os provenientes dos quadrantes NE - ENE e SE. Os ventos de NE predominam entre outubro e março, enquanto os ventos de $S E$ e $S$, relacionados às frentes frias, podem predominar ente abril e setembro (Albino et al. 2005). As ondas originam-se principalmente do Anticiclone Subtropical do Atlântico Sul (ASA), possuindo alturas entre 0,5 a 1,0 m e direções de NNE, NEE, E e ESE, com períodos de 1 a $8 \mathrm{~s}$. No inverno, as ondas do quadrante sul possuem alturas que variam entre 2 e $3 \mathrm{~m}$, podendo alcançar $5 \mathrm{~m}$ e direções de $\mathrm{S} /$ SE, com período de 10-15 s (17 s). Essas ondas do setor sul, associadas às frentes frias, embora sejam menos freqüentes, possuem maior energia do que as do quadrante NE (Albino \& Gomes 2005).

Dos ambientes propícios à colonização bentônica no ES, os arenitos ferruginosos são os mais frequientes estando presentes em toda porção centro - norte do Estado, com largura decrescendo rumo ao sul. Estes recifes pertencem aos depósitos do Grupo Barreiras 

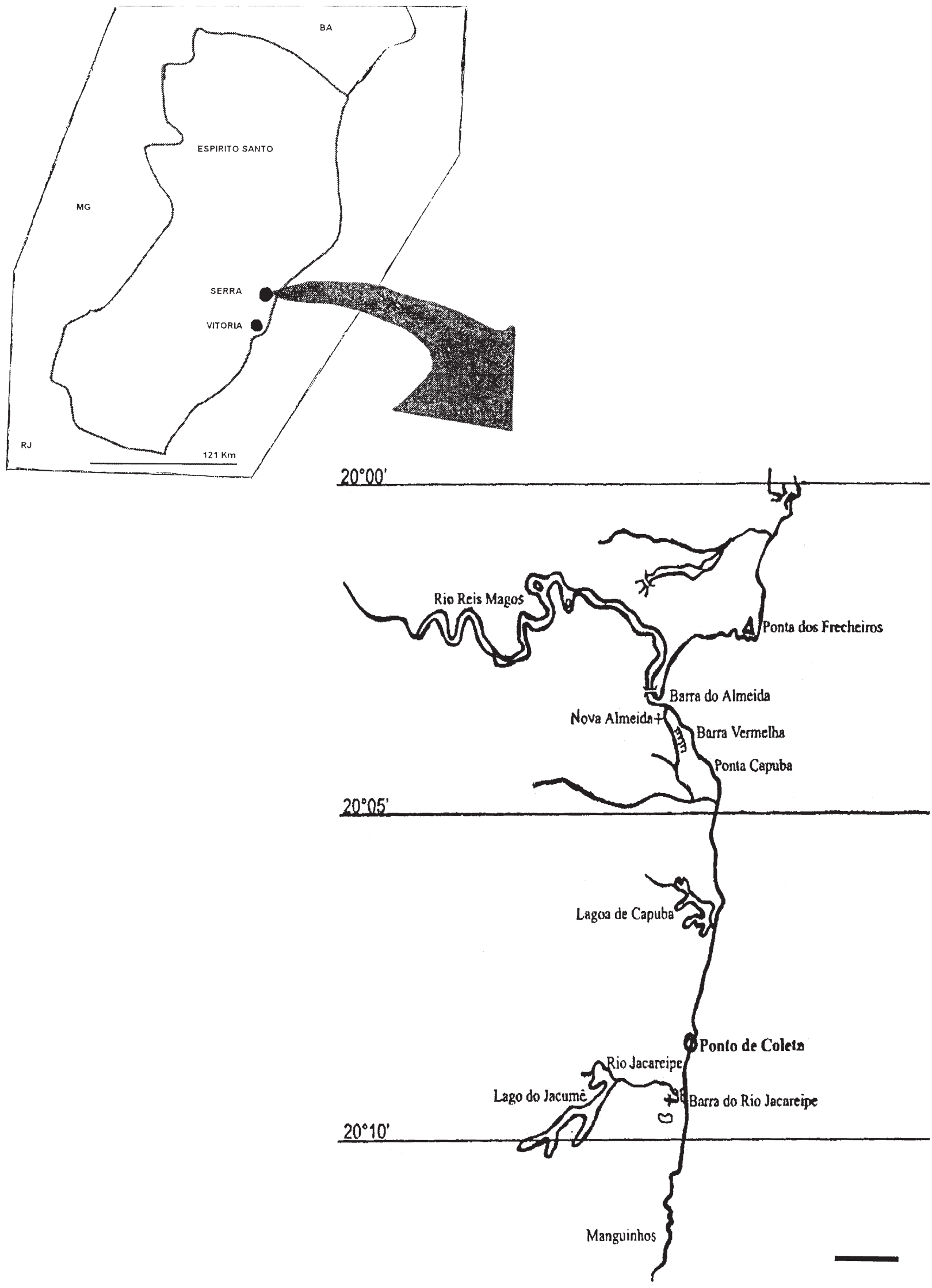

Figura 1. Mapa de localização da área de estudo no centro-norte do Espírito Santo, Brasil. 
e frequentemente encontram-se recobertos por construções biogênicas com predominância de algas calcárias e corais (Albino 1999, Guimarães 2003). Nessa região, a plataforma continental é recoberta principalmente por sedimentos carbonáticos, que se originam da fragmentação das construções fixas carbonáticas pelas ondas, bem como oriundos de concreções móveis tipo rodolitos e fragmentos de esqueletos de moluscos e briozoários, entre outros produtores de carbonatos (Testa, dados não publicados). A alta declividade da plataforma permite a entrada de ondas de alta energia promovendo eficiente transporte e distribuição de sedimentos, ao longo da costa (Albino 1999).

Coleta e análise de dados - O estudo restringiuse às algas fixas ao substrato na zona entre marés, devido a turbidez da água na maior parte do ano, que impede observações visuais da cobertura das algas na comunidade. As amostragens foram realizadas entre julho de 2003 e junho de 2004, nos períodos de verão e inverno, na maré mais baixa registrada para cada período de amostragem, isto é, maré 0,0 a - 0,1.
Foram selecionados dois habitats para o estudo, sendo um mais proximal na lagoa recifal do platô e o outro a $20 \mathrm{~m}$ em direção ao mar na borda do recife. Em cada habitat, as algas foram quantificadas em 10 quadrados aleatórios (cada amostra com $0,0625 \mathrm{~m}^{2}$ ), dispostos em uma linha ao longo de $20 \mathrm{~m}$ de extensão do litoral. Os grupos morfo-funcionais de algas (segundo Steneck \& Dethier, 1994) tiveram sua cobertura estimada em cada quadrado (dividido em 25 sub-quadrados), sendo os grupos com menos de 5\% de cobertura excluídos das análises. No caso dos sedimentos (areia), estes só foram quantificados quando o depósito era igual ou superior a $5 \mathrm{~cm}$ de espessura.

Amostras destrutivas dos quadrados foram usadas para estimar a riqueza, biomassa e freqüência dos táxons. Amostras qualitativas foram feitas em áreas próximas para listagem geral dos táxons. As algas foram retiradas do substrato com o auxílio de espátulas, juntamente com o sedimento acompanhante, o qual foi submetido a análises granulométricas por peneiramento em intervalos de 0,5 (phi) da escala de Wenthworth (1922). Em seguida, foram

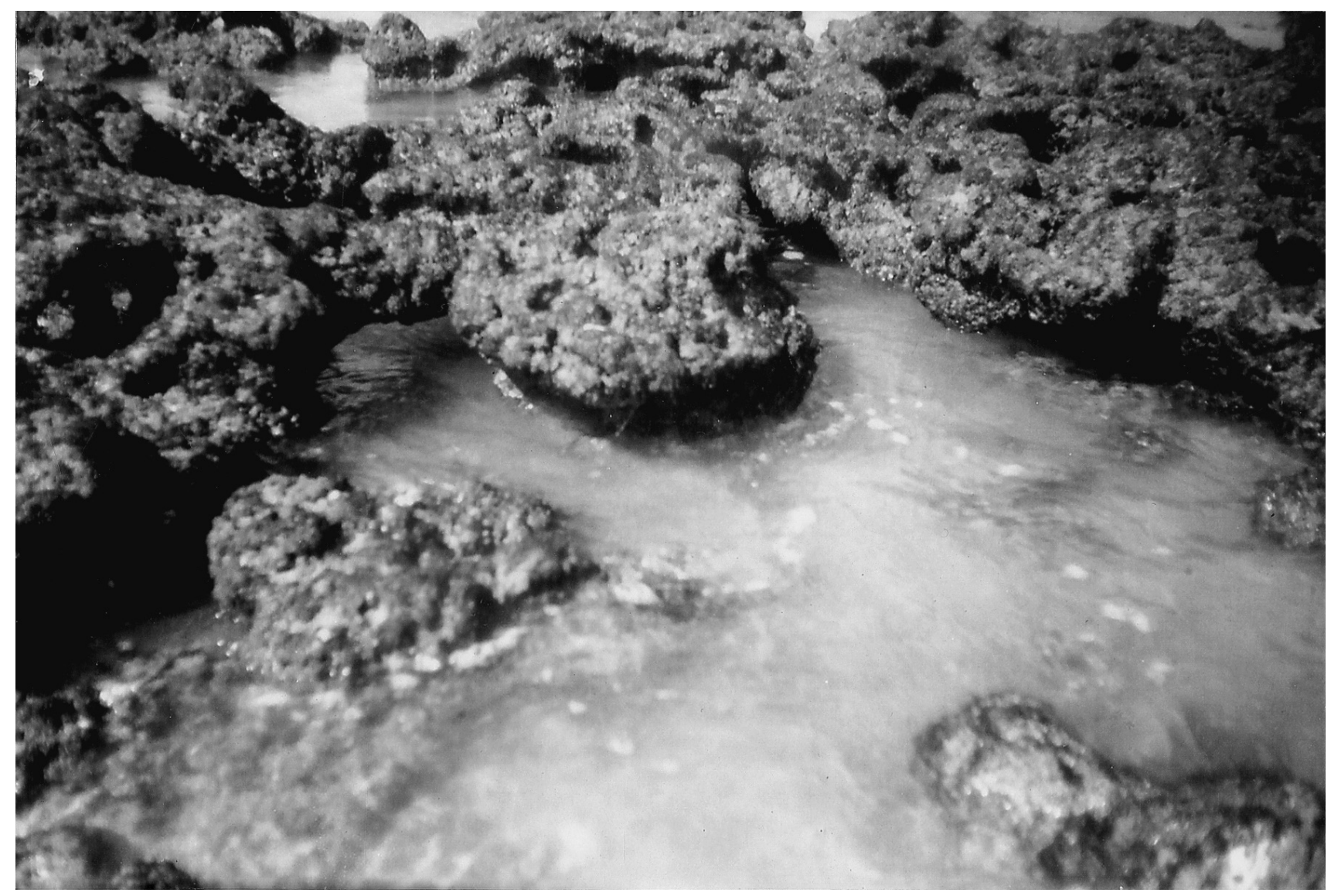

Figura 2. Detalhe do substrato formado por algas calcárias incrustantes na borda do recife. 
acondicionadas em sacos plásticos e congeladas em freezer. No laboratório, as algas foram acondicionadas em frascos contendo formaldeído diluído a $4 \%$ em água do mar. O material conservado foi triado e seccionado, quando necessário, analisado e identificado com o auxílio de estereomicroscópio e microscópio ótico, consultando-se a bibliografia especializada. Os componentes do fitobentos foram identificados em nível de espécie, sempre que possível, exceto as algas calcárias incrustantes, que em função da dificuldade de identificação (Harvey et al. 2005), foram tratadas como uma única entidade denominada UT (Unidade Taxonômica) incrustante. A nomenclatura dos táxons seguiu a classificação de Guiry (2005). O material foi herborizado, registrado e depositado no Herbário do Instituto de Pesquisas Jardim Botânico do Rio de Janeiro (RB).

As amostras identificadas foram levadas em estufa à $60^{\circ} \mathrm{C}$ para a obtenção da massa seca expressa em gramas por área amostrada $\left(0,0625 \mathrm{~m}^{2}\right)$. As espécies de algas calcárias articuladas identificadas foram tratadas como uma única UT nos cálculo de abundância, devido à dificuldade de separar os ramos entrelaçados de cada espécie antes de pesar a amostras. À massa destas algas calcárias aplicou-se um índice de correção, o qual foi obtido através da descalcificação de três amostras, que foram secas e pesadas antes e depois de descalcificadas com ácido acético a 5\%. O índice foi obtido a partir da razão: massa seca calcificada/massa seca descalcificada; sendo a média da razão das três amostras adotada como 'índice de calcificação' para todas as amostras, que apresentam as mesmas espécies de algas calcárias articuladas.

A diversidade foi expressa pelo índice de ShannonWiener $\left(\mathrm{H}^{\prime}\right)$, através da fórmula, $H^{\prime}=\Sigma(p \mathrm{i} \ln p \mathrm{i})$, onde p é a proporção da biomassa de uma dada espécie e ln o seu logarítimo neperiano. A equitabilidade foi calculada pela fórmula $\mathrm{E}=\mathrm{H}^{\prime} / \mathrm{lnS}$ onde, $\mathrm{S}$ é a riqueza de espécies e H' o índice de diversidade. A média dos dados agrupados em primavera/verão e outono/inverno foi empregada nas análises. A análise de variância (ANOVA) unifatorial foi utilizada para verificar se houve diferenças significativas quanto à riqueza, biomassa, diversidade e equitabilidade, na borda e no platô do recife, no inverno e no verão.

A freqüência da espécie foi expressa, em termos percentuais, sendo calculada pelo número de amostras na qual ela se faz presente, sobre o número total de quadrados amostrados $(n=20)$. A freqüência foi calculada para cada espécie dentro dos grupos morfo-funcionais: filamentoso, foliáceo e cilíndrico- corticado, no inverno e verão. Os grupos de algas calcárias articuladas e algas coriáceas não tiveram sua frequiência calculada por não ser possível separar os táxons nas amostras. Também foram levantados dados de cobertura da rocha exposta, rocha coberta por areia e fanerógramas marinhas, essas últimas com hábito psamofítico.

\section{Resultados}

Dados abióticos - Os sedimentos variam de textura arenosa a areia cascalhosa, variando de mal a moderadamente selecionados. A granulometria média dos sedimentos variou de areia fina a muito fina. Os sedimentos são bastante homogêneos, apresentando um pequeno aumento no percentual das areias grossa e muito grossa na borda. Isto se explica pela maior hidrodinâmica encontrada na zona mais distal à praia. Este sedimento é composto principalmente por fragmentos de algas coralíneas (Corallinales).

O período amostral foi marcado por características atmosféricas atípicas. No segundo semestre de 2003, o litoral centro-sul do ES foi atingido por uma forte frente fria oriunda do sul, que trouxe precipitações e ventos fortes permanecendo por vários dias. Esses fatores interferiram na descida da maré, que muitas vezes não oscilavam e elevaram a turbidez. Os primeiros meses do ano, que normalmente são chuvosos e quentes, em 2004, apresentaram baixa pluviosidade e temperaturas amenas.

Dados bióticos - Foram identificados um táxon de Cyanobacteria (2\%), um Bacillariophyta (2\%), 12 Chlorophyta (24\%), quatro Ochrophyta $(7,7 \%)$, 34 Rhodophyta $(65,4 \%)$ e uma fanerógama, num total de 35 gêneros e 51 táxons. Dentre as algas, a ordem melhor representada em número de táxons foi Ceramiales com 10 espécies, seguida de Gracilariales com 7 espécies. Algumas espécies foram registradas somente no verão (9) e outras somente no inverno (três). As rodofíceas, de um modo geral, foram mais representativas em ambas as estações do ano, tanto no habitat da borda como no platô recifal. A Ordem Gelidiales foi a mais representativa nesta classe no verão. As duas demais classes praticamente não tiveram o número de táxons alterado entre os habitats estudados. Dos espécimes encontrados, $82 \%$ apresentaram hábito exclusivamente epilítico, 9,6\% hábito epifítico e 7,7\% ambos os hábitos (tabela 1).

Encontrou-se maior riqueza de espécies no platô do que na borda do recife, independente da época do ano (figura $3 \mathrm{~A}$, ANOVA $\mathrm{p}=0,008$ ). De um modo 
Tabela 1. Lista dos táxons encontrados no platô (P) e borda (B) do recife na Praia de Jacaraípe, no verão e inverno, indicando os respectivos morfotipos e hábitos: $\mathrm{FT}=$ filamentoso, $\mathrm{F}$ = foliáceo, $\mathrm{C}=$ cilíndrico-corticado, $\mathrm{A}=$ calcária articulada, $\mathrm{I}=$ calcária incrustante, $\mathrm{EF}$ = epífita e EL = epilítica.

\begin{tabular}{|c|c|c|c|c|c|c|}
\hline \multirow[t]{2}{*}{ TÁXONS } & \multicolumn{2}{|c|}{ Verão } & \multicolumn{2}{|c|}{ Inverno } & \multirow[t]{2}{*}{ Morfotipo } & \multirow[t]{2}{*}{ Hábito } \\
\hline & $\mathrm{P}$ & $\mathrm{B}$ & $\mathrm{P}$ & $\mathrm{B}$ & & \\
\hline
\end{tabular}

\section{FANERÓGAMA}

Halodule wrightii Ascherson

CHLOROPHYCEAE

\section{Ulvales}

Ulva compressa $\mathrm{L}$.

Ulva fasciata Delile

\section{Cladophorales}

Anadyomene stellata C. Agardh

Cladophora montagneana Kütz.

C. vagabunda (L.) C. Hoek

Chaetomorpha linum (O.F. Müll.) Kütz.

Chaetomorpha sp.

Cladophora ordinata (Børgesem) C. Hoek

\section{Bryopsidales}

Caulerpa cupressoides (H. West) C. Agardh

C. mexicana Sond. ex Kütz.

C. prolifera (Forssk) J.V. Lamour.

\section{Halimeda sp.}

\section{OCHROPHYTA}

Dictyopteris delicatula J.V. Lamour.

Dictyota sp.

Padina gymnospora (Kütz.) Sond.

Sargassum stenophyllum Mart.

\section{RHODOPHYTA}

\section{Gelidiales}

Gelidium floridanum W.R. Taylor

Gelidium sp.

Gelidiella trinitatensis W.R. Taylor

Pterocladiella capillacea (S.G. Gmel) Santel. \& Hommers

Pterocladiella sp. 2

Corallinales

Corallina oficinallis L.

C. panizzoi Schnetter \& U. Richt.

Calcaria incrustante

Jania rubens (L.) J.V. Lamour.

Arthrocardia sp.

\section{Gigartinales}

Hypnea musciformis (Wulfen) J.V. Lamour.

Gymnogongrus griffithsiae (Turner) Mart.

Chondracanthus acicularis(Roth) Fredericq

Peyssonnelia sp.

\section{Ploclamiales}

Plocamium brasiliense (Grev.) M. Howe \& W.R. Taylor

\section{Gracilariales}

Hydropuntia caudata (J. Agardh) Gurgel \& Fredericq

G. cervicornis (Turner) J. Agardh

G. domingiensis (Kütz.) Sond. ex Dickie

G. mammilaris (Montagne) M. Home

Gracilaria sp. 1

Gracilaria sp. 2
EL

$\begin{array}{lll}+ & + \\ + & + & \\ - & + \\ + & + & \\ + & + & - \\ - & + & \\ - & + \\ + & + \\ & \\ + & + \\ - & + \\ + & + \\ - & + \\ & \\ - & + \\ + & - \\ + & + \\ + & -\end{array}$

+
+
-
+
+
+
-
+
+
+
+
-
+
+
+
+

$+$

$\mathrm{F}$

EL F

$\mathrm{EL} / \mathrm{EF}$

F

- F

FT

FT

FT

FT

FT

EL

-

$-$

$+$

EL

EL/EF

EF

EF

EL

EL

EL

EL

EL

EL

EL

EL

EL
EL

EL

EL

EL

EL

EL

EL

EL

EL

EL

EF

EL

EL

EL

EL

EL

EL

EL

EL

EL

EL 
Tabela 1 (continuação)

\begin{tabular}{|c|c|c|c|c|c|c|}
\hline \multirow[t]{2}{*}{ TÁXONS } & \multicolumn{2}{|c|}{ Verão } & \multicolumn{2}{|c|}{ Inverno } & \multirow[t]{2}{*}{ Morfotipo } & \multirow[t]{2}{*}{ Hábito } \\
\hline & $\mathrm{P}$ & $\mathrm{B}$ & $\mathrm{P}$ & $\mathrm{B}$ & & \\
\hline $\begin{array}{l}\text { Gracilariopsis sp. } \\
\text { Halymeniales }\end{array}$ & + & + & + & + & $\mathrm{C}$ & EL \\
\hline $\begin{array}{l}\text { Cryptonemia seminervis (C. Agardh) J. Agardh } \\
\text { Ceramiales }\end{array}$ & - & + & + & + & $\mathrm{C}$ & EL \\
\hline Centroceras clavulatum (C. Agardh) Mont. & + & - & + & - & FT & EL \\
\hline Ceramium deslongchampsii Chauv. ex Duby & + & - & + & + & FT & $\mathrm{EL} / \mathrm{EF}$ \\
\hline Spyridia filamentosa (Wulfen) Harv. & + & - & - & - & FT & EL \\
\hline S. hypnoides (Bory) Papenf. & + & - & - & - & FT & EL \\
\hline Amansia multifida J.V. Lamour. & + & + & - & - & $\mathrm{C}$ & EL \\
\hline Bryothamnion seaforthii (Turner) Kütz. & + & + & + & - & $\mathrm{C}$ & EL \\
\hline Laurencia sp. & - & + & - & - & $\mathrm{C}$ & EL \\
\hline Polysiphonia subitilissima Mont. & - & - & + & - & FT & $\mathrm{EL} / \mathrm{EF}$ \\
\hline Pterosiphonia parasitica (Huds.) Falkenb. & - & - & + & - & FT & EL \\
\hline Osmundaria obtusiloba (C. Agardh) R.E. Norris & + & + & + & + & $\mathrm{C}$ & EL \\
\hline
\end{tabular}

geral, os maiores valores de biomassa foram obtidos no verão para ambos os habitats. A borda recifal teve uma maior biomassa que o platô em ambas as estações do ano (figura 3C, ANOVA $\mathrm{p}=0,01$ para ambas). Em relação à diversidade, observou-se uma interação significativa entre as épocas do ano e os habitats (figura 3B, ANOVA p = 0,01). Na borda encontrouse valores menores que o platô somente no inverno (ANOVA $p=0,01$ ), sendo que não houve diferenças significativas entre os habitats no verão (ANOVA p =0,35). O mesmo padrão foi verificado para o índice
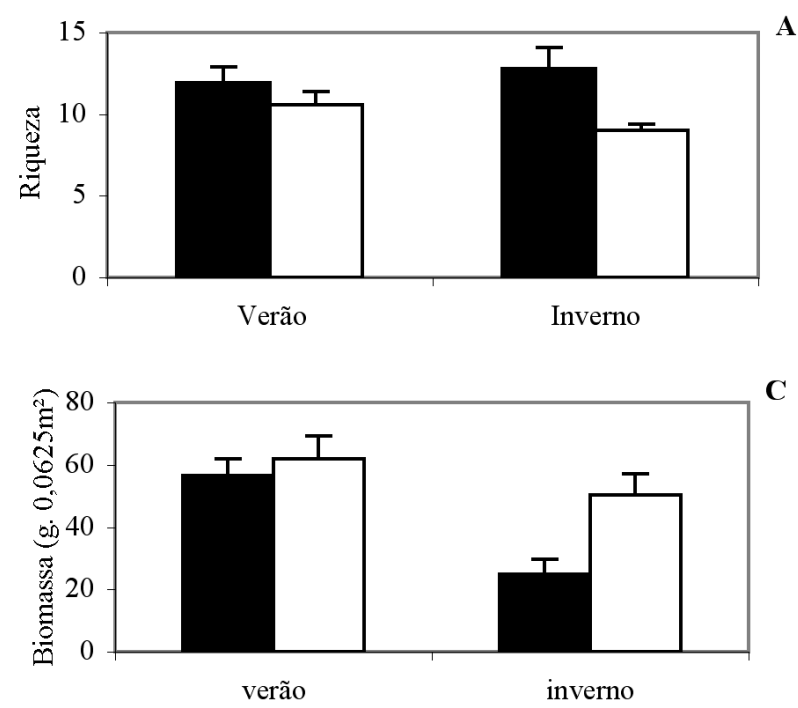

de equitabilidade, havendo uma interação significativa (figura 3D, ANOVA p = 0,02). As diferenças entre os habitats foram significativas somente para o inverno ( $\mathrm{p}=0,35$ no verão e $\mathrm{p}=0,02$ no inverno). Analisando a cobertura dos grupos morfofuncionais das algas (figura 4A, B), estas tiveram maior abundância no verão do que no inverno, exceto pelas filamentosas. As coralináceas articuladas cobriram a maior parte do substrato em ambas as estações. As foliáceas foram o segundo grupo mais abundante no verão e as filamentosas no inverno. Uma drástica redução
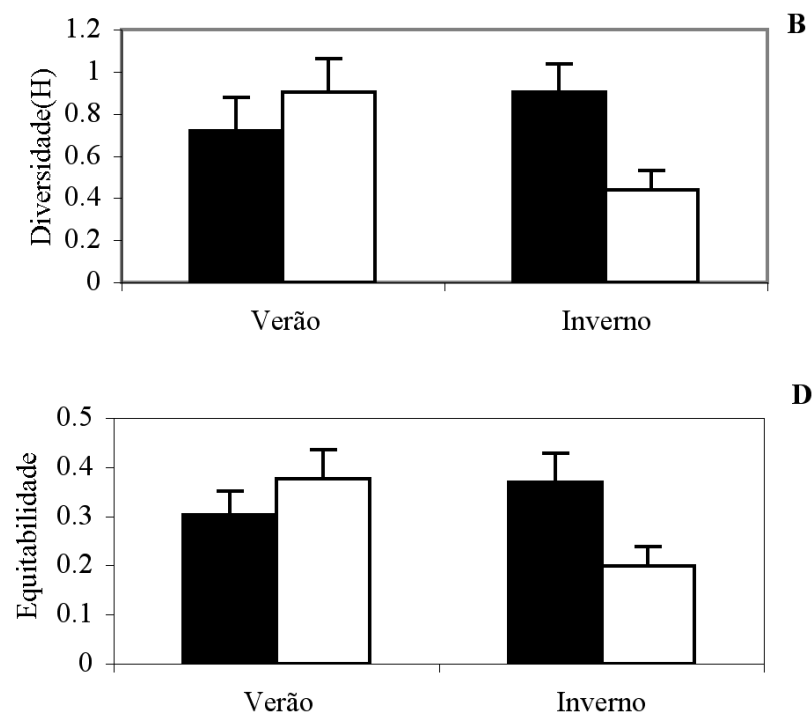

Figura 3. Riqueza (A), diversidade (B), biomassa (C), e equitabilidade (D) de espécies de algas nos hábitats do recife e nas épocas do ano (verão e inverno) ( $\mathbf{\square}=$ platô, $\square=$ borda). 

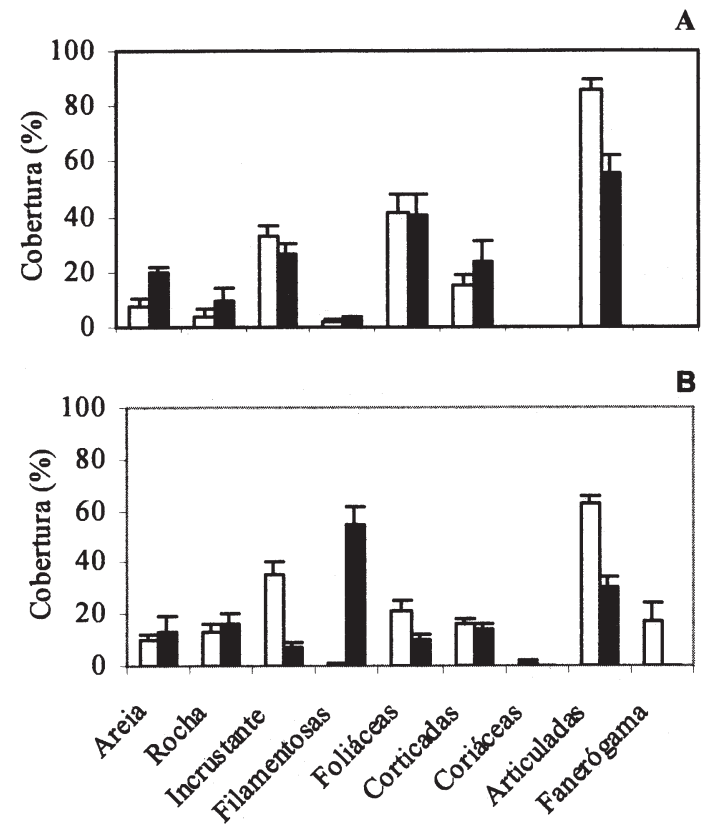

Figura 4. Cobertura dos grupos morfo-funcionais de algas e fanerógamas marinhas e dos tipos de substratos não cobertos por algas, nos hábitats e épocas do ano. A. Verão. B. Inverno. ( $\mathbf{\square}=$ platô, $\square$ = borda).

na cobertura de algas articuladas no platô do recife correspondeu a um incremento das filamentosas do verão para o inverno. Outros grupos são menos abundantes, como as coriáceas, as corticadas e as incrustantes vivas, que tenderam a ter cobertura abaixo de $40 \%$. De um modo geral o substrato esteve coberto por algas e uma fina camada de areia, apresentando-se mais assoreado no verão. As fanerógamas marinhas, representadas por Halodule wrightii Ascherson, só foram amostradas na borda do recife, durante o inverno. Cianobactérias e diatomáceas que formavam colônias macroscópicas sobre as algas incrustantes no platô do recife, durante o inverno, tiveram a menor cobertura. Comparando-se os habitats do recife, observa-se que o grupo das articuladas teve cobertura relativamente maior na borda do que no platô do recife no verão e inverno (figura $4 \mathrm{~A}, \mathrm{~B}, \mathrm{ANOVA} \mathrm{p}=9.10^{-4}$ e $\left.\mathrm{p}=4,8 \cdot 10^{-5}\right)$. As foliáceas e incrustantes também apresentaram maiores valores na borda do que no platô no inverno (ANOVA $p=0,01$ e $p=4,9 \cdot 10^{-5}$ ). As filamentosas tiveram maior cobertura no platô do que na borda (ANOVA $\mathrm{p}=7,3 \cdot 10^{-9}$ ), contrastando com os demais grupos de algas no inverno.

Em relação à massa das algas nas épocas do ano (figura 5A), de um modo geral, os maiores valores encontram-se no verão. Concordando com os dados de cobertura, observa-se que as articuladas tem valores de biomassa relativamente maiores que os outros grupos de algas. Da mesma forma, as foliáceas e corticadas são os segundo grupo mais expressivo em biomassa no verão. Ao comparar os habitats, somente no inverno, apresentaram-se diferenças significativas, sendo as articuladas com maior biomassa na borda e filamentosas no platô (ANOVA $p=0,003$ e $p=0,02$, respectivamente).

A frequiência relativa das espécies variou conforme o grupo morfo-funcional estudado (figura 6). Os grupos das algas coralináceas articuladas e incrustantes estiveram presentes em todas as amostragens, porém as espécies que as compõem não foram quantificadas. Dentre as espécies de filamentosas, as do gênero Cladophora Kütz. e Polysiphonia Grev. foram as mais freqüentes no inverno; além de Cladophora ordinata (Børgesen) C. Hoek que se destacou no verão. As espécies de Spyridia Harv. e Chaetomorpha Kütz. apresentaram as menores freqüências no verão e foram ausentes no inverno, logo, não estão representadas no gráfico (figura 6A). Dentre as foliáceas, Ulva fasciata Delile foi a mais freqüente em ambas as estações (figura 6B). Em relação as corticadas, espécies do gênero Gracilaria Grev. formaram o grupo mais

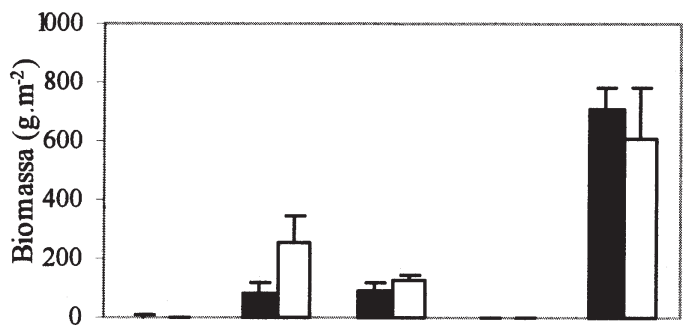

$\mathbf{A}$

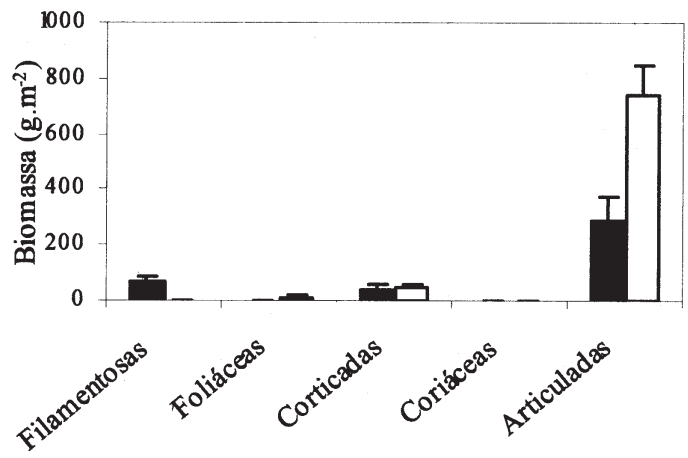

B

Figura 5. Biomassa dos grupos morfo-funcionais nos hábitats e épocas do ano. A. Verão. B. Inverno. ( $\square=$ platô, $\square=$ borda). 

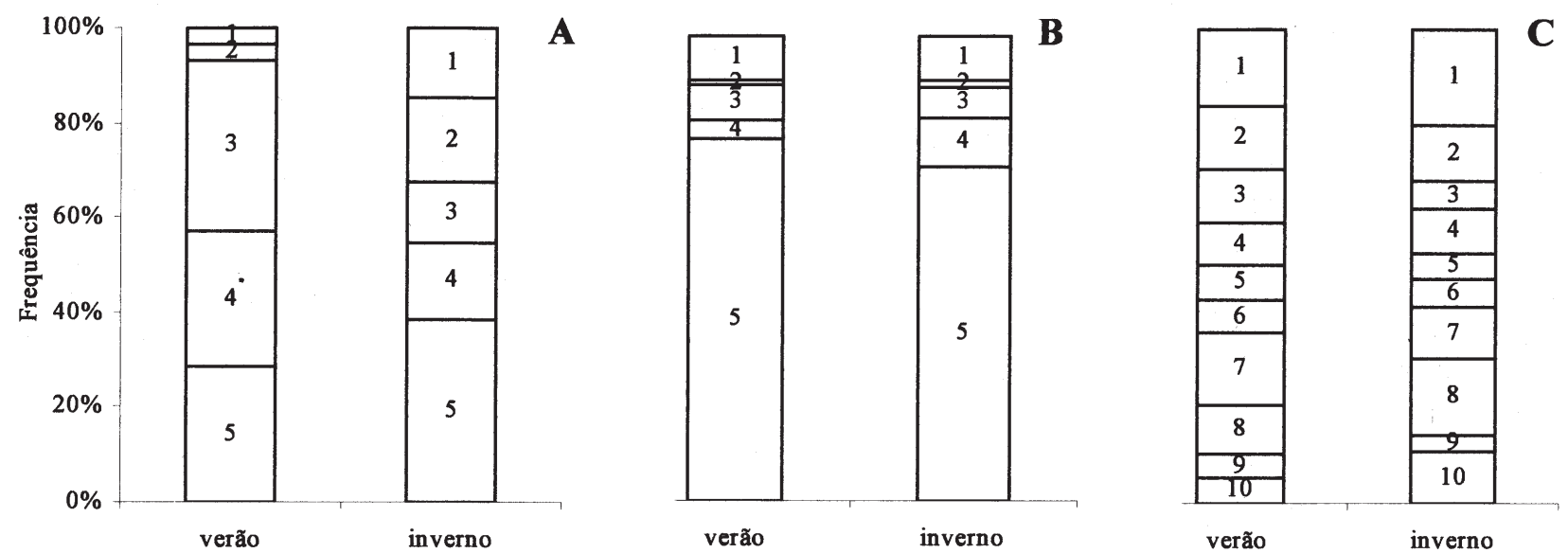

Figura 6. Frequiência das principais espécies dos grupos morfo-funcionais de algas nas épocas do ano (verão e inverno). A. Filamentosas: $1=P$. parasitica, $2=P$. subtilissima, $3=C$. ordinata, $4=C$. vagabunda, $5=C$. montagneana . B. Foliáceas: $1=P$. gymnospora, $2=D$. delicatula, $3=$ A. stellata, $4=U$. compressa, $5=U$. fasciata . C. Corticadas: $1=$ Gracilaria spp., $2=$ G. cervicornis, $3=$ G. domingensis, $4=$ G. mammilaris, $5=$ G. caudata, $6=$ Gracilariopsis sp., $7=$ Ch. acicularis, $8=$ H. musciformis, $9=$ G. griffithsiae, $10=$ G. trinitatensis .

freqüente no verão, seguidas de Hypnea musciformis (Wulfen) J.V. Lamour., que foi mais freqüente no inverno. Além dessas, Chondracanthus acicularis (Roth) Fredericq e Gelidiella trinitatensis W.R. Taylor também foram freqüientes no verão e inverno (figura 6C) respectivamente.

\section{Discussão}

Natureza do substrato - Bioclastos com predominância de fragmentos de algas coralíneas formam o sedimento encontrado no presente estudo. De fato, segundo Albino (1999), as areias da Praia de Jacaraípe são constituídas predominantemente por bioclastos, que constituem 55\% a 94\% da distribuição total, compostos principalmente por algas coralíneas no mesolitoral, além de moluscos e briozoários. Estes sedimentos são encontrados cobrindo porções do recife holocênico. A presença de cavidades, poros e microporos encontradas nos recifes aumentam o potencial de formação de micro-habitats, facilitam a fixação das algas permitindo certo nível de proteção à hidrodinâmica. Dentre os quatro tipos de substratos reconhecidos e distribuídos ao longo da zona costeira do ES, os recifes de corais mortos são os menos estudados, sendo comparáveis aos descritos para a Bahia (Kikuchi \& Leão 1998) e região Nordeste por Leão et al. (2002). Além deste substrato existem no litoral do ES os afloramentos de rochas do embasamento cristalino, rochas de praia ("beachrock") e os afloramentos conhecidos como canga ou crostas lateríticas, que são rochas intemperizadas a ponto de formar uma crosta de óxido de ferro na porção exposta (Martim et al. 1997).

Biota estudada - O Espírito Santo é considerado uma das regiões mais ricas em algas do Brasil, apresentando uma flora de transição, com predominância de rodofíceas em relação a outras classes (Horta 2000). O Espírito Santo apresenta um total de 465 espécies, sendo 105 Chlorophyta, 52 Ochrophyta e 308 Rhodophyta (S.M.P.B. Guimarães, dados não publicados). Pereira (1999), estudando a comunidade de algas do mesolitoral numa praia vizinha à Praia de Jacaraípe, encontrou um maior número de espécies de rodofíceas. O mesmo padrão foi encontrado por Arantes et al. (1995) na Baía de Vitória (ES) e por Nassar et al. (2001) no arquipélago das Três Ilhas (ES).

Os dados, apresentados nesse trabalho, também mostram a predominância de algas rodofíceas no mesolitoral em relação aos demais grupos estudados: uma Cyanobacteria, 12 Chlorophyta, quatro Ochrophyta, 34 Rhodophyta e uma fanerógrama - A riqueza de espécies foi relativamente alta, considerando-se que o esforço amostral foi muito inferior aos realizados por Pereira (1999) em uma praia vizinha. Comparando-se os valores desse trabalho com os encontrados para o litoral do Estado do Espírito Santo (Horta 2000), a região estudada apresenta em apenas um afloramento $17 \%$ de toda a flora do macrofitobentos citada na literatura. 
Dentre as Rhodophyta, a maior riqueza específica para a comunidade estudada foi da Ordem Ceramiales. Esta ordem, só no sul do Estado está representada por metade de todas as Ceramiales citadas para a costa Atlântica tropical e subtropical das Américas (Oliveira Filho 1969). Outros autores também verificaram a predominância das Ceramiales neste Estado, Pereira (1999) para área vizinha à estudada, Arantes et al. (1995) para a Baía de Vitória e Nassar et al. (2001) para o Arquipélago das Três Ilhas. Em termos de abundância, a rodofícea Gracilaria teve maior frequência e dominância nas amostras, entre as algas corticadas, em ambas as estações do ano, parecendo resistir ao soterramento parcial do talo durante os ciclos de maré. Gymnogongrus griffithisae (Turner) Mart. foi encontrado misturado a Chondracanthus acicularis (Roth) Fredericq na borda do recife, o que indica ser esta espécie resistente a maiores estresses ambientais, como batimento. Hypnea musciformis (Wulfen) J.V. Lamour. só foi encontrada em poças ou fendas epifitando outras algas, assim como o observado por Pereira (1999) que a encontrou somente em poças de maré.

Segundo Moura (2000), a baixa intensidade luminosa, os ambientes de águas movimentadas e os curtos períodos de exposição aérea, são fatores que contribuem para o crescimento das coralináceas articuladas do nosso litoral. Em região próxima a estudada, Arantes et al. (1995) encontrou oito espécies de algas articuladas crescendo na forma de tapetes emaranhados, com alta freqüência e distribuição de Jania rubens (L.) J.V. Lamour. Da mesma forma, as espécies articuladas da Praia de Jacaraípe formavam tapetes emaranhados, densos e mistos, com a predominância de Jania rubens (L.) J.V. Lamour , seguida de Corallina oficinallis L. Dentre as algas incrustantes, as coralináceas e Peyssonnelia sp. foram as mais frequientes, mas muitas vezes não foram computadas por estarem encobertas pelo sedimento.

Dentre as Ochrophytas, podemos destacar como mais importantes, no ES, a ordem Dictyotales com 17 táxons, seguida da ordem Fucales com nove táxons (Crispino 2000), assim como o esperado para os trópicos (Lunning 1990). Em outros estados vizinhos ao ES também foi observada a importância desses grupos na riqueza de macroalgas pardas, como o descrito por Nunes $(1998,2005)$ para a Bahia, Szechy \& CordeiroMarino (1991) e Yoneshigue-Valentin (1985), para o norte do Rio de Janeiro. A presença de Sargassum stenophyllum Mart. na área de estudo, aparenta estar restrita às irregularidades do substrato, que os mantém protegidos da ação das ondas e da dessecação na maré baixa. De fato, Sargassum C. Agardh tende a alcançar elevados valores de biomassa em comunidades de locais protegidos e de energia hidrodinâmica moderada, onde não tenha havido distúrbios freqüentes (Széchy \& Paula 2000). Isso explica a ocorrência e a baixa dominância de Sargassum C. Agardh na maior parte do substrato na comunidade estudada. Outras algas pardas como Dictyota J.V. Lamour., Dictyopteris J.V. Lamour. e Padina Adans também só foram encontradas em cavidades, assim como o observado por Pereira (1999).

Dentre as Chlorophyta, Barata (2004) encontrou no litoral sul do Espírito Santo Bryopsidales como a ordem mais significativa em termos de riqueza de espécies, assim como o observado para o Estado da Bahia (Nunes 1998, 2005). Este padrão também é o esperado para o litoral do Brasil (Horta 2001) e outras regiões tropicais (Lunning 1990). Contudo, esses dados contrapõem aos registrados para a Praia de Jacaraípe, onde a ordem Cladophorales predominou em riqueza. De fato, a elevada freqüencia de Cladophora Kütz. no inverno, deve resultar da retirada de algas devido ao estresse mecânico que permite a re-colonização freqüente destas espécies oportunistas. Entre as foliáceas, Ulva fasciata Delile é o taxon dominante e mais freqüente, em ambas as estações do ano. O mesmo foi encontrado por Reis \& Yoneshigue-Valentin (1996) que citaram esse gênero como oportunista e tolerante a amplas variações de parâmetros ambientais.

Os principais aspectos favoráveis à ocorrência das algas na praia estudada é a própria presença deste tipo de substrato e a hidrodinâmica moderada-intensa, que permitem a oxigenação das águas (Hurd 2000) e retirada de parte dos sedimentos. Entre os aspectos desfavoráveis, podemos citar a elevada turbidez, durante os períodos de outono e inverno. A turbidez, associada à re-suspensão dos sedimentos, pode limitar o desenvolvimento de certos grupos de algas no local. O predomínio das rodofíceas pode ser explicado pela melhor adaptação que esse grupo possui à alta turbidez da água, pois apresentam um amplo espectro de absorção da luz, em relação às outras classes (Kain \& Norton 1990, Luning 1990).

A ação severa das ondas aparentemente inibiu ou limitou o estabelecimento de macroalgas na zona intramareal pelo distúrbio físico. De um modo geral, atribui-se a baixa biomassa das algas, com exceção das algas calcárias articuladas, ao estresse mecânico local. De fato, a ação severa das ondas pode remover ou 
limitar o crescimento de determinados grupos de algas (Norton 1991). Em região próxima, Nassar et al. (2001) encontrou uma menor riqueza em área sujeita à ação de fortes ondas. A hidrodinâmica, portanto, deve ser considerada como a principal responsável pela grande quantidade de algas arribadas encontradas na praia, principalmente no inverno. A hidrodinâmica também age de outra forma, além de arrancar as algas do substrato, re-suspende o sedimento e, consequentemente, provoca abrasão do sedimento no substrato podendo impedir a fixação de esporos (Vadas et al. 1992). No entanto, os esporos que se acumulam nas poças ou nas fendas ou reentrâncias da superfície, tem uma maior chance de fixação, devido à heterogeneidade do substrato (Figueiredo et al. 1997). Isto explica a maior biomassa encontrada nas freqüentes e pequenas depressões na borda do recife, principalmente para algas articuladas e foliáceas. Por outro lado, a maior abundância de algas filamentosas oportunísticas foi no platô durante o inverno, quando a abrasão do sedimento re-suspenso pelas ondas é mais forte. Provavelmente isto se deve ao fato de as algas filamentosas tapearem sedimentos, que é deletério para outros grupos.

Na borda do recife, a dominância de algas calcárias articuladas demonstrou uma distribuição diferenciada da biomassa entre as espécies, o que resultou numa baixa equitabilidade. Desta forma, algas calcárias articuladas aparentemente limitaram o desenvolvimento de outras algas. Algas perenes que formam tapetes emaranhados ("turfs") são superiormente competitivas, visto ao preenchimento do espaço pela densidade de ramos por área (Olson \& Lubchenco 1990, Arantes et al. 1995). Desta forma, espécies oportunistas menos competitivas devem ter sido excluídas, o que explica a menor riqueza e diversidade neste habitat. De acordo com o modelo que prevê a distribuição da abundância dos grupos morfo-funcionais de algas, as maiores biomassas e as mais alta diversidade são encontradas em ambientes com distúrbio moderado e alta produtividade (Steneck \& Dethier 1994). Nesses locais, observa-se que as algas dominantes geralmente são as de vida-longa, tal como as algas calcárias articuladas coriáceas e as corticadas.

Na Praia de Jacaraípe, as algas calcárias articuladas e algas filamentosas densamente entrelaçadas retêm grande quantidade de sedimentos arenosos (areia fina a muito fina), o que provavelmente as protege da dessecação na maré baixa, visto nunca terem apresentado vestígios desse estresse. $\mathrm{O}$ fato de os sedimentos não apresentarem a fração lamosa passa a ser um importante diferencial, pois as areias são mais facilmente retiradas pelas ondas do que a lama.
A deposição de sedimentos somados a abrasão pela hidrodinâmica local, portanto, podem ter contribuído para que a riqueza de espécies encontrada na comunidade em estudo fosse baixa. As fanerógamas marinhas, encontradas próximas à borda do recife, também retinham grande quantidade de sedimentos e acumulavam matéria orgânica sobre as algas calcárias incrustantes, em leves depressões do substrato junto à algumas macroalgas. Segundo Steneck \& Dethier (1994), locais ocupados por comunidades algais em ambientes com alta produtividade, podem estar sob um distúrbio físico alto, logo, apresentam poucos grupos de algas: algas crostosas, algas calcificadas e pequenas algas filamentosas em tapetes ("turfs").

Outros distúrbios - O estresse de dessecação durante as marés baixas aparentemente não afetou a comunidade estudada, visto que o tempo de exposição dessas algas é muito baixo. O substrato só fica $100 \%$ exposto em marés negativas, que são raras, quando uma fina lâmina d'água cobre o talo das algas. Somado a isso, não houve marés baixas diurnas no período de verão. Desse modo, as algas permaneceram por quatro meses quase que totalmente submersas e, conseqüentemente, as algas provavelmente puderam se desenvolver em maior abundância nesta época. $\mathrm{O}$ impacto provocado pelo turismo local é um problema que pode estar atuando nesta comunidade, podendo ser responsável pela redução da diversidade de algas. Durante todo o ano, observou-se banhistas que durante caminhadas pisoteiam o recife nas marés baixas e arrancam algas de grande porte. Nassar et al. (2001), também citou este distúrbio como um dos responsáveis pela redução da riqueza. Potenciais herbívoros não foram observados, contudo, a presença destes não pode ser descartada no local porque os trabalhos foram realizados na baixamar, quando muitos herbívoros devem ter reduzido o consumo.

Diferença significativa entre a borda e o platô do recife quanto à riqueza, biomassa, diversidade $\mathrm{e}$ equitabilidade só foram encontradas no inverno. $\mathrm{O}$ grupo das algas coralináceas articuladas teve a maior freqüiencia, cobertura e biomassa. A divisão Rhodophyta e a ordem Ceramiales apresentaram maior riqueza de espécies. O tipo de substrato, a turbidez e a hidrodinânica local estão entre os fatores que provavelmente mais influenciaram a estrutura da comunidade local.

\section{Agradecimentos}

À Fundação Ecossistemas do Espírito Santo, pelo treinamento e bibliografias. Ao Departamento de 
Ecologia e Recursos Naturais (DERN) da Universidade Federal do ES por ceder infraestrutura. Ao Instituto de Pesquisas do Jardim Botânico do Rio de Janeiro pelo treinamento. A Maria Beatriz de Barros Barreto pela identificação da espécie de Ceramium.

\section{Literatura citada}

Albino, J. 1999. Processos de sedimentação atual e morfodinâmica das praias de Bicanga à Povoação-ES. Tese de Doutorado, Universidade de São Paulo, São Paulo.

Albino, J. \& Gomes, C.R. 2005. Descrição dos aspectos oceanográficos do litoral do ES. Instituto do Milênio, Projeto RECOS - Uso e apropriação dos recursos costeiros. Subgrupo: modelagem, monitoramento, erosão e ocupação costeira. http://www.mileniodomar. org.br (acesso em 04.06.2005).

Albino, J., Vale, C.C. \& Gomes, R.C. 2005. Descrição climática do litoral do ES. Instituto do Milênio, Projeto RECOS - uso e apropriação dos recursos costeiros. Subgrupo: modelagem, monitoramento, erosão e ocupação costeira. http://www.mileniodomar.org.br (acesso em 04.06.2005).

Arantes, P.V.S., Nassar, C.A.G. \& Gestinari, L.M.S. 1995. Comunidade de algas calcárias articuladas na Baía do Espírito Santo. Nerítica 9: 33-48.

Behar, L. 1972. Clorofíceas do litoral sul do estado do ES. I- Siphonales e Siphonocladales. Dissertação de Mestrado, Universidade de São Paulo, São Paulo.

Barata, D. 2004. Clorofíceas marinhas bentônicas do Estado do Espírito Santo. Dissertação de Mestrado, Instituto de Botânica de São Paulo, São Paulo.

Crispino, L.M.B. 2000. Feofícias do litoral do Estado do Espírito Santo. Dissertação de Mestrado, Instituto de Biociências, Universidade Estadual Paulista, Rio Claro, São Paulo.

DHN. 2004. Diretoria de Hidrografia e Navegação. Tábuas de marés. http://www.mar.mil.br/dhn/chn/tabuas/index. htm (acesso em 24/02/2004).

Figueiredo, M.A.O., Norton, T.A. \& Kain, J.M. 1997. Settlement and survival on two intertidal crustose algae. Journal of Experimental Marine Biology and Ecology 213: 247-260.

Gomes, C.A., Yoneshigue-Valentim, Y., Maurat, M.C.S. \& Mitchell, G.J.P. 1989. Feofíceas do litoral norte do Estado do Espírito Santo. Ínsula 19 (suplemento): 143-168.

Guimarães, S.M.P.B. 1990. Rodofíceas marinhas bentônicas do Estado do Espírito Santo: Ordem Cryptonemiales. Tese de Doutorado, Universidade de São Paulo, São Paulo.

Guimarães, S.M.P.B. 2003. Uma análise da diversidade da flora marinha bentônica do Estado do Espírito Santo, Brasil. Hoehnea 30: 11-19.
Guimarães, S.M.P.B. \& Pereira, A.P.V. 1993. Rodofíceas marinhas bentônicas do estado do Espírito Santo, Brasil: gênero Calliblepharis (Cystocloniaceae, Gigartinales). Hoehnea 20: 35-46.

Guiry, M.D. \& Dhonncha, E. 2005. AlgaeBase. World electronic publication. National University of Ireland, Galway. http://www.algaebase.com (acesso em 07.07.2006).

Harvey, A., Woelkerling, W., Farr, T., Neill, K. \& Nelson, W. 2005. Coralline algae of Central New Zeland. An identification guide to common crustose species. Niwa Press, Wellington.

Horta, P.A. 2000. Macroalgas do infralitoral do sul e sudeste do Brasil: taxonomia e biogeografia. Tese de Doutorado, Universidade de São Paulo, São Paulo.

Horta, P.A., Amâncio E., Coimbra, C.S. \& Oliveira, E.C. 2001. Considerações sobre a distribuição e origem da flora de macroalgas marinhas brasileiras. Hoehnea 28: 243-265.

Hurd, C.L. 2000. Water motion, marine macroalgal physiology, and production. Journal of Phycology 36: 453-472.

INMET. 2005. Instituto Nacional de Meteorologia. http// www.inmet.gov.br (acesso em 17.05.2005).

Kain, J.M. \& Norton, T.A. 1990. Marine Ecology. In: K.M. Cole \& R.G. Sheath (eds.). Biology of the red algae. Cambridge University Press, New York, pp. 377-422.

Kikuchi, R.K.P. \& Leão, Z.M.A.N. 1998. The effects of Holocene sea-level fluctuation on reef development and coral community structure, northern Bahia, Brazil. Anais da Academia Brasileira de Ciências 70: 159-171.

Leão, Z.M.A.N., Kikuchi, R.K.P. \& Testa, V. 2002. Corals and coral reefs of Brasil. In: J. Cortez (ed). Latin America Coral Reefs. Elsevier Science, Amsterdam, pp. 9-52.

Leão, Z.M.A.N \& Dominguez, J.M.L. 2000. Tropical coast of Brazil. Marine Pollution Bulletim 41: 112-122.

Lüning, K. 1990. Seaweeds: their environment, biogeography and ecophysiology. New York, WileyInterscience.

Mitchell, G.J.P., Nassar, C.A.G., Maurat, M.C.S. \& Falcão, C. 1990. Tipos de vegetação marinha da Baía do Espírito Santo (Brasil). In: S. Watanabe (ed.). Anais do II Simpósio de Ecossistemas da Costa Sul e Sudeste Brasileira: estrutura, função e manejo, Águas de Lindóia, SP. Academia de Ciências de São Paulo, São Paulo, pp. 202-214.

Martin, L., Suguio, K. \& Flexor, J.M. 1993. As flutuações do nível do mar durante o Quaternário superior e a evolução geológica de deltas Brasileiros. Boletim IG / USP, Publicação Especial 3: 55-65.

Martin, L., Suguio, K., Dominguez, J.M.L. \& Flexor, J.M. 1996. Coastal Quaternary formations of the southern part of the State of Espírito Santo (Brazil). 
Anais da Academia Brasileira de Ciências 68: 389404.

Moura, C.W.N. 2000. Algas coralináceas com genículo (Rhodophyta, Corallinales) do litoral do Brasil. Tese de Doutorado, Universidade de São Paulo, São Paulo.

Nassar, C.A.G., Souza, R.R. \& Yoneshigue-Valentin, Y. 2001. Inventário florístico das algas marinhas bentônicas do Arquipélago das Três Ilhas (Espírito Santo, Brasil): estudo preliminar. Leandra 16: 1-10.

Nunes, J.M.C. 1998. Catálogo de algas marinhas bentônicas do Estado da Bahia, Brasil. Acta Botânica Malacitana 23: 5-21.

Nunes, J.M.C. 2005. Rodofíceas marinhas bentônicas do Estado da Bahia, Brasil. São Paulo. Tese de Doutorado, Universidade de São Paulo, São Paulo.

Norton, T.A. 1991. Confliting constraints on the form of intertidal algae. British Phycological Journal 26: 203-218.

Oliveira, E.C. 1969. Algas marinhas do sul do Estado do ES (Brasil): I- Ceramiales. Boletim da Faculdade de Filosofia, Ciências e Letras da Universidade de São Paulo, série Botânica 26: 1-297.

Oliveira, E. C. 1977. Algas Marinhas Bentônicas do Brasil. Tese de Livre-docência, Universidade de São Paulo, São Paulo.

Olson, A.M. \& Lubchenco, J. 1990. Competition in seaweeds: linking plant traits to competitive outcomes. Journal of Phycology 26: 1-6.

Pereira, A.P.V. 1999. Análise espaço-temporal da comunidade de algas marinhas bentônicas sobre couraças lateríticas na Praia da Baleia - Manguinhos - Serra (ES). Dissertação de Mestrado, Universidade Federal do Espírito Santo, Vitória.
Reis, R.P. \& Yonesshigue-Valentim, Y. 1996. Distribuição das macroalgas na lagoa de Araruana, Estado do Rio de Janeiro, Brasil. Revista Brasileira de Botânica 19: 77-85.

Steneck, R.S. \& Dethier, M.N. 1994. A funcional group approach to the structure of algal - dominated communities. Oikos 69: 476-498.

Széchy, M.T.M. \& Paula, E.J. 2000. Padrões estruturais quantitativos de bancos de Sargassum (Phaeophyta, Fucales) do litoral dos Estados do RJ e SP, Brasil. Revista Brasileira de Botânica 23: 121-132.

Széchy, M.T.M. \& Cordeiro-Marino, M. 1991. Feofícias do litoral norte do Estado do Rio de Janeiro, Brasil. Hoehnea 18: 205-241.

Vadas, R.L., Johnson, S. \& Norton, T.A. 1992. Recruitment and mortality of early post-settlement stages of benthonic algae. British Phycological Society 27: 331-351.

Villaça, R. 2002. Recifes Biológicos. In: R.C. Pereira \& A.S. Gomes (eds). Biologia Marinha. Interciência, Rio de Janeiro, pp. 1-350.

Valentim, J. \& Moreira, A.P. 1978. A matéria orgânica zooplanctônica nas águas de ressurgência de Cabo Frio (Brasil). Anais da Academia Brasileira de Ciências 50: 103-122.

Wentworth, C.K. 1922. A scale of grade and class term for clastic sediments. Journal of Geology 30: 377-392

Yoneshigue-Valentin, Y. 1985. Taxonomie et ecologie des algues marines dans la region de Cabo Frio (Rio de Janeiro-Brésil). Tese de Doutorado, Université d'Aix-Marseille III, Aix-en-Provence. 